\title{
Birth weight and risk of asthma in 3-9-year-old twins: exploring the fetal origins hypothesis
}

\author{
Karin Kindlund, ${ }^{1}$ Simon Francis Thomsen, ${ }^{1}$ Lone Graff Stensballe, ${ }^{2}$ Axel Skytthe, ${ }^{3}$ \\ Kirsten Ohm Kyvik, ${ }^{3,4}$ Vibeke Backer, ${ }^{1}$ Hans Bisgaard ${ }^{5}$
}

'Department of Respiratory Medicine, Bispebjerg Hospital, Copenhagen, Denmark ${ }^{2}$ Danish Epidemiology Science Centre, Statens Serum Institut, Copenhagen, Denmark ${ }^{3}$ The Danish Twin Registry, University of Southern Denmark, Odense, Denmark ${ }^{4}$ Institute of Regional Health Services Research, University of Southern Denmark, Odense, Denmark ${ }^{5}$ Danish Pediatric Asthma Center, University Hospital of Copenhagen, Gentofte, Denmark

\section{Correspondence to} Dr Simon Francis Thomsen, Department of Respiratory Medicine, Bispebjerg Hospital, DK-2400 Copenhagen NV Denmark; sft@city.dk

Received 27 March 2009 Accepted 7 November 2009 Published Online First 8 December 2009

\section{ABSTRACT}

Aim To examine the relationship between birth weight and risk of asthma in a population of twins.

Methods Birth weight of all live twins (8280 pairs) born in Denmark between 1994 and 2000 was linked to information on asthma obtained from parent-completed questionnaires at age 3-9 years. Conditional logistic regression was used to calculate the risk of asthma.

Results Subjects with a history of asthma at age $3-9$ years weighed on average $122 \mathrm{~g} \mathrm{(95 \%} \mathrm{Cl} 85$ to 160) less at birth than subjects who had not developed asthma, $p<0.001$. There was a linear increase in asthma risk with decreasing birth weight, OR (per $100 \mathrm{~g}) 1.04$ (95\% Cl 1.03 to 1.05$), p<0.001$. Within twin pairs, the lower birthweight twin had a significantly increased risk of asthma compared with the heavier co-twin $111.3 \%$ vs 9.9\%), OR 1.30 (95\% Cl 1.10 to 1.54), $p=0.002$. The result remained significant after adjusting for sex, birth length and Apgar score, OR 1.31 (95\% Cl 1.03 to 1.65), $p=0.027$. The risk tended to be higher in monozygotic co-twins compared with dizygotic co-twins, especially for high birth weight differences.

Conclusions Low birth weight is a risk factor for asthma independently of gestational age, sex, birth length and Apgar score, but this may be due, in part, to residual non-genetic confounding factors. This finding lends support to the "fetal origins hypothesis" suggesting undisclosed prenatal determinants for the risk of asthma.

\section{INTRODUCTION}

A higher concordance for asthma and atopy in monozygotic (MZ) than in dizygotic (DZ) twins has been taken as evidence of a significant genetic component for these diseases. ${ }^{1}$ However, there is increasing evidence that the prenatal environment, particularly impaired fetal growth, plays an important role in determining a person's risk of disease later in life. ${ }^{2}$ Notably, conditions such as diabetes and cardiovascular disease have been linked to impaired intrauterine growth leading to the formulation of the "fetal origins hypothesis'; that is, that these diseases may begin as a result of abnormal development during fetal life rather than, or in addition to, a genetic predisposition. ${ }^{3}$

Several studies have examined the association between birth anthropometry and atopic diseases, but with conflicting results. In particular, low birth weight has been associated with atopic diseases in a large proportion of the studies, ${ }^{4-9}$ but not in all, ${ }^{10-15}$ whereas a number of studies have reported a higher risk of atopic diseases in subjects with high birth weight. ${ }^{4} 7816-18$ Birth length has also been associated with asthma in one study, ${ }^{13}$ but not in others, ${ }^{14}$ as has high ponderal index. ${ }^{10} 1117$ Furthermore, a large head circumference at birth has been associated with hay fever, ${ }^{19}$ high immunoglobulin $\mathrm{E}$ $(\operatorname{IgE})^{1320}$ and development of asthma, ${ }^{13}{ }^{14}$ although evidence is circumstantial. ${ }^{11}$

Twin studies offer a powerful approach to examine the impact of genes and environment on human diseases. Particularly, studies of twin pairs discordant for a disease outcome or an exposure can be used to detect whether an association between exposure and outcome is influenced by genetic and non-genetic confounding factors. The aim of this study was to examine the association between birth weight and asthma in a Danish nationwide twin cohort and to test for underlying genetic and non-genetic confounding between these traits.

\section{METHODS \\ Study population}

The study population comprised all live-born twins (8280 pairs) who were born in Denmark between 1994 and 2000 and included in the nationwide Danish Twin Registry. In 2003, a multidisciplinary questionnaire on health and disease was sent to these twin cohorts to be answered by the parents of the twins. Zygosity of same-sex twins was established using four similarity questions, which assign zygosity correctly in $>95 \%$ of cases. ${ }^{21}$ Subjects with a history of asthma were identified on the basis of an affirmative response to the question "Has your child ever had asthma?" Information about birth weight, birth length, gestational age and Apgar score was acquired from the Danish Medical Birth Registry. Body mass index (BMI) was calculated as birth weight $(\mathrm{kg})$ divided by the square of birth length (m). Apgar score is a measure of physical condition after delivery and is based on five criteria (skin colour, heart rate, reflex irritability, muscle tone and respiration). Data on birth weight were available for 15908 subjects (96.1\%), on asthma for 10773 subjects (65.1\%) and on zygosity for 13154 subjects $(79.4 \%)$; a total of 5169 twin pairs had complete data on both birth weight and asthma, and of these 4954 also had known zygosity (867 MZ and 4087 DZ twin pairs) (figure 1)

\section{Statistical analysis}

$\chi^{2}$ and $t$ tests were used to compare the distribution of birth characteristics between groups. A 1:1 matched conditional logistic regression analysis (co-twin control analysis) was applied in order to estimate the impact of birth weight on the risk of asthma. The matching was done with the lower birthweight twin in each pair being the case and the higher birthweight twin being the control. Risk 
Figure 1 Flowchart of available information in the study. DZ, dizygotic; MZ, monozygotic.

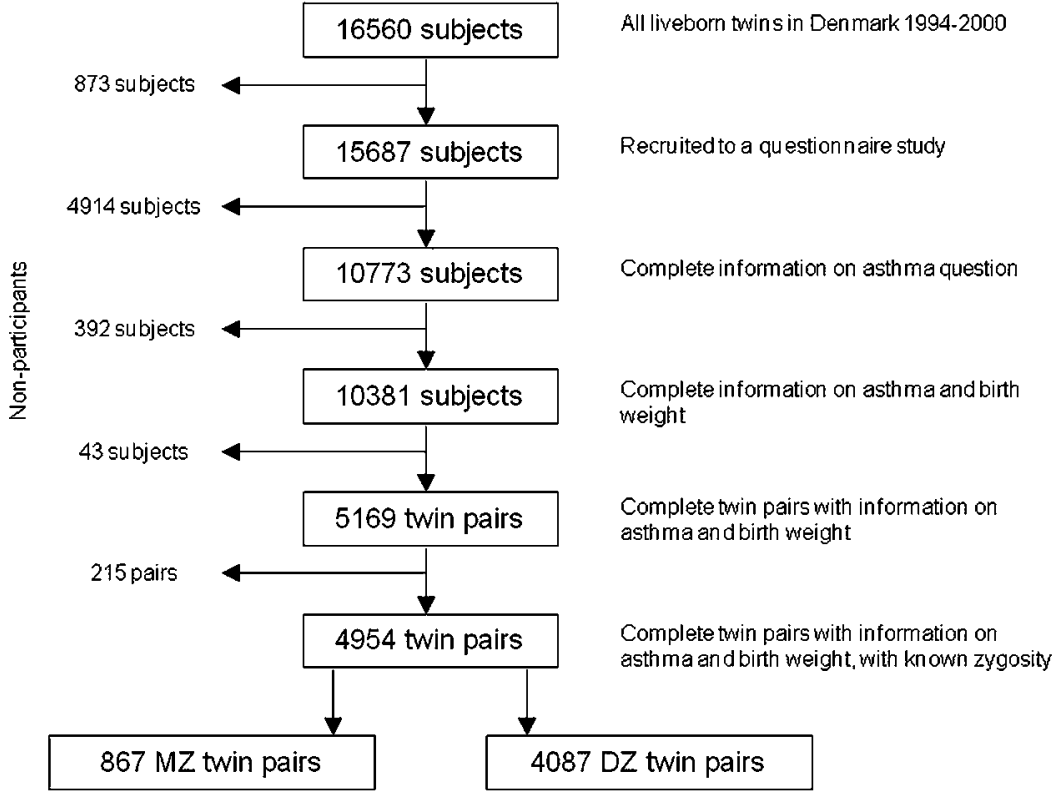

estimates were given as the OR with 95\% CI. DZ same-sex and DZ opposite-sex twin pairs were pooled in the analysis, and sex, birth length and Apgar score were included as covariates. In the co-twin control analysis, a higher risk of asthma in DZ co-twins compared with $\mathrm{MZ}$ co-twins indicates genetic confounding between birth weight and asthma, whereas a higher risk of asthma in $\mathrm{MZ}$ co-twins compared with $\mathrm{DZ}$ co-twins indicates non-genetic confounding between birth weight and asthma. ${ }^{22}$ Data were analysed with the statistical package SPSS 16.0 (SPSS, Chicago, Illinois, USA). The local Scientific Ethical Committee approved the protocol.

\section{RESULTS}

Birth characteristics of the studied sample are given in table 1. A total of $42 \%$ of the population weighed $<2500 \mathrm{~g}$ at birth and $49 \%$ were born preterm (before 37 weeks). The intrapair correlation in birth weight was 0.80 among $M Z$ twins and 0.73 among DZ twins, and the intrapair correlation in birth length was 0.83 in MZ twins and 0.74 in DZ twins. The correlation between birth weight and birth length within the same individual was 0.87 . In total, $10.7 \%$ of the population had a history of asthma at age 3-9 years.

Subjects with a history of asthma weighed on average $122 \mathrm{~g}$ (95\% CI 85 to 160) less at birth than subjects who had not developed asthma, $\mathrm{p}<0.001$ (table 2). There was a linear increase in asthma prevalence with decreasing birth weight, OR (per 100 g) 1.04 (95\% CI 1.03 to 1.05), $p<0.001$ (figure 2). Significant differences between subjects with and without asthma were also observed for sex, age at examination, birth length, birth BMI and gestational age (table 2).

Co-twin control analysis showed that the lower birthweight twin had a history of asthma in $11.3 \%$ of the cases, whereas his or her heavier co-twin had a history asthma in $9.9 \%$ of the cases, OR 1.30 (95\% CI 1.10 to 1.54), $\mathrm{p}=0.002$. The result remained significant after adjusting for sex, birth length and Apgar score, OR 1.31 (95\% CI 1.03 to 1.65$), p=0.027$. The risk tended to be attenuated in DZ twins compared with $M Z$ twins, indicating some degree of confounding due to non-genetic risk factors, particularly for large differences in birth weight. However, formal tests for heterogeneity of risks between $M Z$ and DZ twins were not statistically significant (table 3 ). We subsequently tested for effects of birth length and birth BMI on the risk of asthma using the same co-twin control methodology. The risk of asthma in the shorter twin at birth relative to the longer twin adjusted for sex, birth weight and Apgar score was OR 1.35 (95\% CI 1.01 to 1.80), $\mathrm{p}=0.046$, whereas the risk of asthma in the twin with the lowest BMI at birth adjusted for sex and Apgar score was OR $1.22(95 \%$ CI 1.02 to 1.45$), p=0.031$. Tests for effects in twin pairs with larger differences in these measures were unreliable due to limited information in the data, but there was an indication of attenuated effect sizes in DZ twins relative to $M Z$ twins, consistent with the findings for birth weight. Since there was no marginal

Table 1 Birth characteristics of a sample of Danish twin pairs, 3-9 years of age

\begin{tabular}{|c|c|c|c|c|c|c|c|c|}
\hline Zygosity & Number (\%) & $\begin{array}{l}\text { Birth } \\
\text { weight } \\
\text { mean (SD) }\end{array}$ & $\begin{array}{l}\text { Birth length } \\
\text { mean (SD) }\end{array}$ & $\begin{array}{l}\text { Birth BMI } \\
\text { (SD) }\end{array}$ & $\begin{array}{l}\text { Gestational } \\
\text { age (SD) }\end{array}$ & $\begin{array}{l}\text { Apgar } \\
\text { score }\end{array}$ & $\begin{array}{l}\text { Current } \\
\text { age (SD) }\end{array}$ & $\begin{array}{l}\text { Asthma } \\
(\%)\end{array}$ \\
\hline $\mathrm{MZ}$ & 1950 (11.8) & 2508 (547) & $47.75(3.33)$ & $11.00(1.30)$ & 253.03 (17.39) & $9.70(1.03)$ & $5.92(1.99)$ & $213(11.8)$ \\
\hline DZ-ss & $4854(29.3)$ & $2580(582)$ & $48.10(3.35)$ & $11.15(1.45)$ & $254.59(17.84)$ & $9.73(0.94)$ & $5.86(1.98)$ & $499(11.0)$ \\
\hline DZ-os & $6350(38.3)$ & 2567 (594) & 47.99 (3.59) & $11.14(1.52)$ & $253.97(19.31)$ & $9.68(1.16)$ & $5.90(2.00)$ & 412 (10.3) \\
\hline All DZ & 11204 (67.7) & 2572 (589) & $48.04(3.49)$ & 11.15 (1.49) & 254.24 (18.69) & $9.70(1.07)$ & $5.88(1.99)$ & $911(10.7)$ \\
\hline UZ & 3406 (20.6) & 2418 (671) & $47.01(4.45)$ & $10.94(1.66)$ & $249.30(23.85)$ & $9.48(1.62)$ & $6.03(2.02)$ & $31(6.9)$ \\
\hline Males & $8491(51)$ & 2567 (623) & $48.03(3.82)$ & $11.13(1.52)$ & $252.52(20.35)$ & $9.63(1.25)$ & $5.92(1.98)$ & $698(12.7)$ \\
\hline Females & 8069 (49) & 2498 (583) & $47.56(3.57)$ & $11.05(1.49)$ & 253.67 (19.22) & $9.68(1.15)$ & $5.92(2.01)$ & 457 (8.7) \\
\hline Total & $16560(100)$ & 2534 (605) & $47.80(3.71)$ & $11.09(1.51)$ & 253.08 (19.81) & $9.65(1.20)$ & $5.92(2.00)$ & $1155(10.7)$ \\
\hline
\end{tabular}

Birth weight is given in $\mathrm{g}$, birth length in $\mathrm{cm}, \mathrm{BMl}$ is in $\mathrm{kg} / \mathrm{m}^{2}$, gestational age is in days and current age is in years.

Means and proportions are calculated from available data for the individual variables.

BMI, body mass index; DZ-os, dizygotic opposite sex; DZ-ss, dizygotic same sex; MZ, monozygotic; UZ, unknown zygosity. 
Table 2 Birth characteristics of subjects with and without asthma in a sample of Danish twin pairs, 3-9 years of age

\begin{tabular}{llllr}
\hline \multirow{2}{*}{ Measure } & Asthma & & & \\
\cline { 2 - 5 } & Yes $\mathbf{n = 1 1 5 5}$ & $\mathbf{N o} \mathbf{n}=\mathbf{9 6 1 8}$ & Difference $\mathbf{( 9 5 \%} \mathbf{~ C l )}$ & p Value \\
\hline Birth weight & 2467 & 2589 & $122(87$ to 158$)$ & $<0.001$ \\
Birth length & 47.54 & 48.14 & $0.60(0.39$ to 0.81$)$ & $<0.001$ \\
Birth BMl & 10.93 & 11.17 & $0.23(0.14$ to 0.32$)$ & $<0.001$ \\
Gestational age & 250.50 & 255.02 & $4.52(3.32$ to 5.72$)$ & $<0.001$ \\
Apgar score & 9.69 & 9.74 & $0.05(-0.01$ to 0.11$)$ & 0.120 \\
Current age & 6.23 & 5.83 & $0.41(0.29$ to 0.53$)$ & $<0.001$ \\
Sex & & & & \\
$\quad$ Males & 12.7 & 87.3 & 1.00 & \\
$\quad$ Females & 8.7 & 91.3 & $0.65(0.58$ to 0.74$)$ & $<0.001$ \\
Zygosity & & & & \\
$\quad$ MZ & 11.8 & 88.2 & 1.00 & 0.183 \\
$\quad$ DZ & 10.7 & 89.3 & $0.90(0.77$ to 1.05$)$ & \\
\hline
\end{tabular}

Measures are mean values except for sex and zygosity (prevalence). Birth weight is in $\mathrm{g}$ birth length is in $\mathrm{cm}, \mathrm{BMI}$ is in $\mathrm{kg} / \mathrm{m}^{2}$, gestational age is in days, current age is years.

Means and proportions are calculated from available data for the individual variables.

Sex and zygosity difference are ORs.

$\mathrm{BMI}$, body mass index; DZ, dizygosity; MZ, monozygosity.

effect of Apgar score, we did not test for a main effect of this parameter in the co-twin control analysis.

\section{DISCUSSION}

This study showed that subjects with a history of asthma at age 3-9 years weighed significantly less at birth compared with subjects without asthma. The risk of asthma increased linearly with decreasing birth weight. The effect of birth weight was independent of sex, birth length, Apgar score and gestational age. However, residual non-genetic confounding factors may play a role in the association between birth weight and asthma, exemplified by the observation that the risk of asthma in birthweight-discordant $M Z$ twins tended to be higher than in $D Z$ twins, particularly for large differences in birth weight between the two twins in a pair. This finding substantiates the "fetal origins hypothesis"; that is, that the risk of common chronic diseases later in life may be the result of fetal programming rather than, or in addition to, genetic vulnerability.

Impaired fetal growth has, besides atopic diseases, been associated with a range of disorders such as, for example, diabetes, cardiovascular disease and schizophrenia. ${ }^{3} 23$ These observations indicate that programming of major hormonal systems during fetal life and adaptations made by the fetus in response to undernutrition could lead to permanent physiological and metabolic changes that increase the subject's risk of disease throughout life. ${ }^{2}$ Previous studies have suggested a strong genetic component for these diseases based on a higher similarity among $\mathrm{MZ}$ than among DZ twins. However, an alternative explanation for these findings may be a more similar early envi-

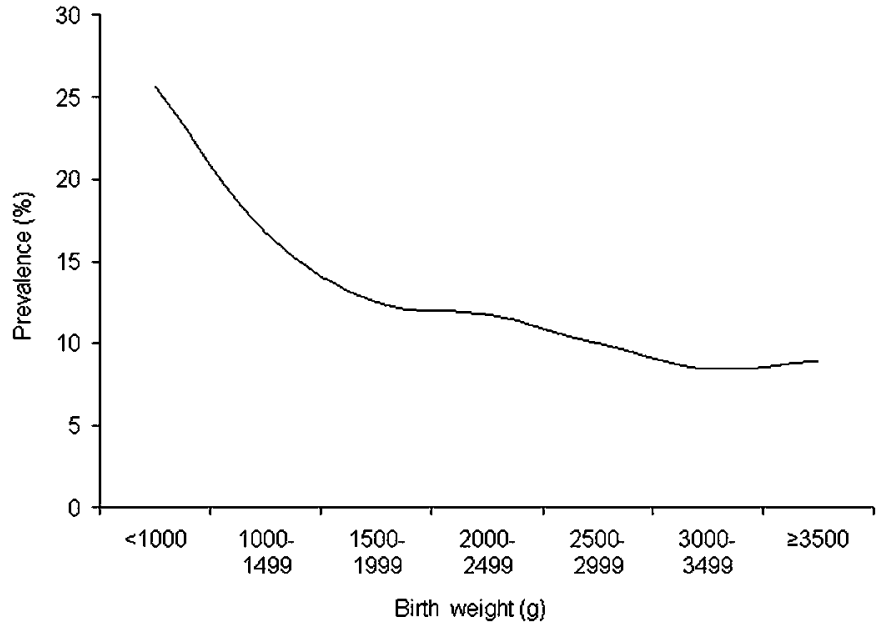

Figure 2 Prevalence of asthma according to birth weight in Danish twin pairs, 3-9 years of age.

ronment in $\mathrm{MZ}$ twins compared with $\mathrm{DZ}$ twins. $\mathrm{MZ}$ twins are monochorionic (and sometimes monoamniotic), share their placentas to a greater extent and have vascular anastomoses between their circulations. A resulting exchange of hormones, signalling and nutritional factors between the two twins during fetal life may therefore facilitate a more similar development of their physiology and a resulting similar risk of disease later in life. ${ }^{2}$ This being said, there is an undeniably strong hereditary component for asthma. ${ }^{1}$ Our result must therefore be accommodated in the explanations of the aetiology of asthma bearing this in mind.

When interpreting the results of our study it must be recognised that data on asthma were parent reported, and therefore that bias due to recall and subjective interpretation of disease status is likely. In contrast, anthropometric measures at birth were collected from a central registry with objective data from midwives' reports and were thus independent of the disease outcome. Furthermore, co-twin control analysis enabled us to adjust indirectly for a range of unmeasured factors, such as genotype, gestational age, and maternal smoking during pregnancy and during the early life of the child. Still, residual confounding could, besides intrauterine factors, be due to respiratory infections, particularly in low birthweight infants, perinatal intensive care, dietary factors, birth order effects and factors relating to household and upbringing.

Twin pregnancies differ from singleton pregnancies in several aspects, which may affect the generalisability of our study. Mothers of twins, especially of DZ twins, tend to be older and of higher parity. Duration of gestation is shorter, twins are of lower birth weight and their neonatal morbidity and mortality is higher than that of singletons. Over $40 \%$ of twins are born

Table 3 Risk of asthma in the lower birthweight twin relative to the higher birthweight twin in a sample of Danish twin pairs, 3-9 years of age

\begin{tabular}{|c|c|c|c|c|c|c|c|}
\hline \multirow{2}{*}{$\begin{array}{l}\text { Birth weight } \\
\text { difference (g) }\end{array}$} & \multicolumn{2}{|l|}{ All twin pairs } & \multicolumn{2}{|l|}{ MZ twin pairs } & \multicolumn{2}{|l|}{ DZ twin pairs } & \multirow{2}{*}{$\frac{\mathrm{OR}_{\mathrm{MZ}}=\mathrm{OR}_{\mathrm{DZ}}}{\text { p Value }^{*}}$} \\
\hline & OR $(95 \% \mathrm{CI})$ & p Value & OR (95\% CI) & p Value & OR $(95 \% \mathrm{CI})$ & p Value & \\
\hline Any difference $†$ & 1.31 (1.03 to 1.65$)$ & 0.027 & $1.33(0.72$ to 2.46$)$ & 0.356 & $1.29(1.08$ to 1.54$)$ & 0.005 & 0.935 \\
\hline$\geq 100$ & 1.26 (1.05 to 1.57$)$ & 0.015 & $1.75(0.86$ to 3.56$)$ & 0.122 & $1.23(1.01$ to 1.49$)$ & 0.042 & 0.516 \\
\hline$\geq 200$ & $1.29(1.04$ to 1.60$)$ & 0.019 & 1.71 (0.68 to 4.35$)$ & 0.257 & $1.28(1.02$ to 1.61$)$ & 0.030 & 0.661 \\
\hline$\geq 300$ & $1.40(1.09$ to 1.81$)$ & 0.008 & $3.33(0.92$ to 12.11$)$ & 0.067 & 1.37 (1.05 to 1.77$)$ & 0.019 & 0.413 \\
\hline$\geq 400$ & $1.21(0.91$ to 1.81$)$ & 0.192 & $2.33(0.60$ to 9.02$)$ & 0.220 & $1.21(0.90$ to 1.63$)$ & 0.202 & 0.524 \\
\hline$\geq 500$ & $1.20(0.84$ to 1.71$)$ & 0.322 & $2.50(0.49$ to 12.89$)$ & 0.273 & 1.17 (0.81 to 1.69$)$ & 0.402 & 0.538 \\
\hline
\end{tabular}

*Test for heterogeneity between $\mathrm{OR}$ for $\mathrm{MZ}$ and $\mathrm{DZ}$ twin pairs.

†Adjusted for sex, birth length and Apgar score.

$\mathrm{MZ}$, monozygotic; DZ, dizygotic. 
preterm (before 37 weeks) and $\sim 50 \%$ weigh $<2500$ g at birth. There is some evidence to suggest differential asthma morbidity in twins compared with singletons. ${ }^{54}$ In particular, some studies have observed a lower prevalence of asthma in twins, possibly in part because of cross-infections between twins resulting in a $T$ helper 1 (Th1)-driven immune response. ${ }^{25}$

We were left with a relatively low number of $M Z$ twin pairs discordant for asthma (42 in total), which constitute the informative families for the co-twin control study. Furthermore, there was little twin-to-twin variation in birth weight within $M Z$ pairs. Notably, the correlation in birth weight between $M Z$ twins was 0.80 , resulting in few twin pairs with high birth weight differences who were also discordant for asthma.

We conclude that low birth weight is a risk factor for asthma independently of gestational age, sex, birth length and Apgar score. However, the association between birth weight and asthma may to some extent be influenced by residual nongenetic confounding factors. This observation lends support to the "fetal origins hypothesis" suggesting undisclosed prenatal determinants for the risk of asthma.

\section{Competing interests None.}

Ethics approval This study was approved by the local Scientific Ethical Committee.

Provenance and peer review Not commissioned; externally peer reviewed.

\section{REFERENCES}

1. Los H, Postmus PE, Boomsma DI. Asthma genetics and intermediate phenotypes: a review from twin studies. Twin Res 2001;4:81-93.

2. Phillips DIW. Fetal programming or genes? In: Spector TD, Snieder H, MacGregor AJ, eds. Advances in twin and sib-pair analysis. London, UK: Greenwich Medical Media Ltd, 2000;79-90.

3. Barker DJ, Hales CN, Fall CH, et al. Type 2 (non-insulin-dependent) diabetes mellitus, hypertension and hyperlipidaemia (syndrome $\mathrm{X}$ ): relation to reduced fetal growth. Diabetologia 1993;36:62-7.

4. Shaheen So, Sterne JA, Montgomery SM, et al. Birth weight, body mass index and asthma in young adults. Thorax 1999;54:396-402

5. Braback L, Hedberg A. Perinatal risk factors for atopic disease in conscripts. Clin Exp Allergy 1998;28:936-42.
6. Steffensen FH, Sørensen HT, Gillman MW, et al. Low birth weight and preterm delivery as risk factors for asthma and atopic dermatitis in young adult males. Epidemiology 2000;11:185-8.

7. Olesen $\mathbf{A B}$, Ellingsen $A R$, Olesen $\mathrm{H}$, et al. Atopic dermatitis and birth factors: historical follow up by record linkage. BMJ 1997;314:1003-8.

8. Svanes C, Omenaas E, Heuch JM, et al. Birth characteristics and asthma symptoms in young adults: results from a population-based cohort study in Norway. Eur Respir J 1998;12:1366-70.

9. Kiechl-Kohlendorfer U, Horak E, Mueller W, et al. Neonatal characteristics and risk of atopic asthma in schoolchildren: results from a large prospective birth-cohort study. Acta Paediatr 2007:96:1606-10.

10. Räsänen M, Kaprio J, Laitinen T, et al. Perinatal risk factors for asthma in Finnish adolescent twins. Thorax 2000;55:25-31.

11. Laerum BN, Svanes C, Wentzel-Larsen T, et al. The association between birth size and atopy in young North-European adults. Clin Exp Allergy 2005;35:1022-7.

12. Laerum BN, Svanes C, Gulsvik A, et al. Is birth weight related to lung function and asthma symptoms in Nordic-Baltic adults? Respir Med 2004;98:611-18.

13. Leadbitter $\mathbf{P}$, Pearce N, Cheng $\mathrm{S}$, et al. Relationship between fetal growth and the development of asthma and atopy in childhood. Thorax 1999;54:905-10.

14. Fergusson DM, Crane J, Beasley $\mathrm{R}$, et al. Perinatal factors and atopic disease in childhood. Clin Exp Allergy 1997;27:1394-401.

15. Girolomoni G, Abeni D, Masini C, et al. The epidemiology of atopic dermatitis in Italian schoolchildren. Allergy 2003:58:420-5.

16. Räsänen $\mathbf{M}$, Kaprio J, Laitinen $\mathrm{T}$, et al. Perinatal risk factors for hay fever-a study among 2550 Finnish twin families. Twin Res 2001;4:392-9.

17. Yuan W, Basso 0, Sorensen HT, et al. Fetal growth and hospitalization with asthma during early childhood: a follow-up study in Denmark. Int J Epidemiol 2002;31:1240-5

18. Remes ST, Patel SP, Hartikainen AL, et al. High birth weight, asthma and atopy at the age of 16 yr. Pediatr Allergy Immunol 2008;19:541-3

19. Katz KA, Pocock SJ, Strachan DP. Neonatal head circumference, neonatal weight, and risk of hayfever, asthma and eczema in a large cohort of adolescents from Sheffield, England. Clin Exp Allergy 2003;33:737-45.

20. Godfrey KM, Barker DJ, Osmond C. Disproportionate fetal growth and raised $\operatorname{lgE}$ concentration in adult life. Clin Exp Allergy 1994;24:641-8.

21. Christiansen L, Frederiksen H, Schousboe K, et al. Age- and sex-differences in the validity of questionnaire-based zygosity in twins. Twin Res 2003:6:275-8.

22. Duffy DL. The co-twin control study. In: Spector TD, Snieder H, MacGregor AJ, eds Advances in twin and sib-pair analysis. London, UK: Greenwich Medical Media Ltd, 2000:53-66.

23. Nilsson $\mathbf{E}$, Stålberg $\mathrm{G}$, Lichtenstein $\mathrm{P}$, et al. Fetal growth restriction and schizophrenia: a Swedish twin study. Twin Res Hum Genet 2005;8:402-8.

24. Strachan DP, Moran SE, Mclnneny K, et al. Reduced risk of hospital admission for childhood asthma among Scottish twins: record linkage study. BMJ 2000; $321: 732-3$.

25. Thomsen SF, Kyvik KO, Backer V. A note on twin-singleton differences in asthma. Twin Res Hum Genet 2008;11:161-4. 